11

\title{
Оптические свойства тонких пленок фталоцианинов цинка по данным спектральной эллипсометрии
}

\author{
() В.Н. Кручинин ${ }^{1}$, Д.Д. Клямер ${ }^{2,3}$, Е.В. Спесивцев ${ }^{1}$, С.В. Рыхлицкий ${ }^{1}$, Т.В. Басова ${ }^{2,3}$ \\ ${ }^{1}$ Институт ффизики полупроводников им. А.В. Ржанова Сибирского отделения РАН, \\ 630090 Новосибирск, Россия \\ ${ }^{2}$ Институт неорганической химии Сибирского отделения РАН, \\ 630090 Новосибирск, Россия \\ ${ }^{3}$ Новосибирский государственный университет, \\ 630090 Новосибирск, Россия \\ e-mail: vladd.kruch@yandex.ru
}

Поступила в редакцию 21.07.2018 г.

Исследованы оптические свойства тонких пленок на основе незамещенного и тетрафторзамещенного фталоцианинов цинка в спектральном диапазоне длин волн 250-1000 nm, полученных методом физического осаждения из газовой фазы. Методом спектроэллипсометрии показано, что пленки на основе фталоцианинов цинка однородны по толщине и оптическим характеристикам, сильно поглощают свет в видимой области спектра и имеют характерные максимумы поглощения, обусловленные электронными переходами в системе сопряженных двойных связей колец фталоцианинов. Введение фторзаместителей в периферийные положения молекулы фталоцианина цинка приводит к усилению поглощения света и сдвигу основного максимума поглощения в длинноволновую область спектра (батохромный сдвиг). Для описания спектров поглощения света использована оптическая дисперсионная модель Лоренца-Друде. Показано, что пленки на основе смеси фталоцианинов могут быть хорошо описаны в рамках модели эффективной среды Бруггемана.

DOI: $10.21883 /$ OS.2018.12.46946.229-18

\section{Введение}

Тонкие пленки фталоцианинов металлов $(\mathrm{Zn}, \mathrm{Pb}, \mathrm{Co}$, $\mathrm{Ni}, \mathrm{Cu})$ и их производных в последние годы все чаще используют в микроэлектронных приборах благодаря их уникальным электрофизическим, оптическим и физикохимическим свойствам [1-3].

Особый интерес представляют фторзамещенные фталоцианины металлов. Их синтез был описан достаточно давно [4], однако интерес к этим соединениям вновь возрос только в последние 20 лет. Это связано с обнаружением у них уникальных электрофизических свойств. В отличие от большинства фталоцианинов, являющихся полупроводниками $p$-типа, для их перфторзамещенных производных характерна проводимость $n$-типа $[5,6]$. По сравнению с незамещенными фталоцианинами структура, фазовый состав и оптические свойства пленок фторзамещенных фталоцианинов описаны существенно меньше. Наиболее хорошо исследованными являются фталоцианины меди $\mathrm{CuPcF}_{16}[7,8]$, цинка $\mathrm{ZnPcF}_{16}$ [9] и ванадила $\mathrm{VOPcF}_{16}[10-13]$.

В серии работ $[5,11,14]$ была показана возможность эпитаксиального роста пленок гексадекафторзамещенных фталоцианинов ванадила и цинка на поверхностях $\mathrm{NaCl}, \mathrm{KCl}$ и $\mathrm{KBr}$ при термическом осаждении из газовой фазы. Кроме того, показано, что структура пленок $\mathrm{ZnPcF}_{16}$ зависит не только от материала подложки, но также от толщины пленки и температуры подложки во время осаждения [15]. В работе [16] с помощью электронной дифракции исследовано поведение тонких пленок $\mathrm{VOPcF}_{16}$, осажденных при различных температурах подложки. Авторы работы [13] изучили фазовый переход в пленках $\mathrm{VOPcF}_{16}$ при нагревании. Имеется целый ряд работ по исследованию полевых транзисторов с использованием слоев $\mathrm{MPcF}_{16}$.

В то же время данных по исследованию тетрафторированных фталоцианинов металлов и тонких пленок на их основе в литературе представлено существенно меньше. В работе [5] пленки ZnPcF4 наряду с пленками других фторзмещенных фталоцианинов $(\mathrm{ZnPc}, \mathrm{ZnPcF} 8$ и $\left.\mathrm{ZnPcF}_{16}\right)$ были изучены в качестве активных слоев полупроводниковых материалов. Исследовались не только закономерности роста пленок, но и их электрофизические и сенсорные свойства на кислород. Было установлено, что с ростом степени фторирования происходит изменение морфологии пленок (уменьшается размер кристаллитов и их ориентация), а также закономерно изменяются спектральные и электрические свойства. $\mathrm{B}$ наших недавних работах показано, что пленки $\mathrm{MPcF}_{4}$ $(\mathrm{M}=\mathrm{Zn}, \mathrm{Co}, \mathrm{Cu})$ могут служить перспективными активными слоями адсорбционно-резистивных сенсоров для определения аммиака в воздухе $[17,18]$. Кроме того, в литературе указывается, что химическое взаимодействие фталоцианинов с другими веществами приводит к существенному изменению спектров поглощения пленок, поэтому исследование оптических свойств фталоцианинов представляет большой интерес.

Целью настоящей работы является исследование оптических свойств тонких пленок, полученных на основе незамещенного $(\mathrm{ZnPc})$ и тетрафторзамещенного 
$\left(\mathrm{ZnPcF}_{4}\right)$ фталоцианинов цинка, методом физического осаждения из газовой фазы в спектральном диапазоне $250-1000 \mathrm{~nm}$.

\section{Методы исследований}

\section{Образцы}

Тетрафторзамещенный фталоцианин цинка $\mathrm{ZnPcF}_{4}$ синтезировали путем нагревания смеси 4-фторофталонитрила (Aldrich) и безводного хлорида цинка $\mathrm{ZnCl}_{2}$ $(4: 1)$ в стеклянной ампуле при $220^{\circ} \mathrm{C}$ в течение $6 \mathrm{~h}$. Полученный продукт, а также незамещенный фталоцианин цинка (ZnPc, Aldrich) очищали методом градиентной сублимации в вакууме $\left(1.3 \cdot 10^{-3} \mathrm{~Pa}\right)$ при $450 \circ \mathrm{C} . \mathrm{ZnPcF}_{4}$ представлял собой смесь четырех изомеров, которые не разделялись сублимацией.

Тонкие пленки $\mathrm{ZnPc}$ и $\mathrm{ZnPcF}_{4}$ получали методом физического осаждения из газовой фазы на предварительно подготовленные кремниевые подложки $\mathrm{Si}(100)$ марки КДБ-7.5 при температуре подложки $60-80^{\circ} \mathrm{C}$ и величине остаточного давления при испарении $\sim 10^{-5} \mathrm{mmHg}$. Температура испарения фталоцианинов $440^{\circ} \mathrm{C}$. Скорость осаждения $0.6 \mathrm{~nm} \cdot \mathrm{s}^{-1}$. Были получены однослойные структуры $\mathrm{Si} / \mathrm{ZnPc}$ и $\mathrm{Si} / \mathrm{ZnPcF}_{4}$, двухслойные структуры $\mathrm{Si} / \mathrm{ZnPc} / \mathrm{ZnPcF}_{4}$ и $\mathrm{Si} / \mathrm{ZnPcF}_{4} / \mathrm{ZnPc}$ послойным осаждением $\mathrm{ZnPc}$ и $\mathrm{ZnPcF}_{4}$, а также смешанные пленки $\mathrm{ZnPc}+\mathrm{ZnPcF}_{4}$. Смешанные пленки получены путем совместного испарения $\mathrm{ZnPc}$ и $\mathrm{ZnPcF}_{4}(1: 1)$ при тех же условиях.

Данные о составе, толщинах и оптических свойствах пленок образцов, исследованных в работе, описаны в таблице. Для удобства восприятия в таблице представлены расчетные значения $n$ и $k$ для длины волны $632.8 \mathrm{~nm}$, часто используемой в $\mathrm{He}-\mathrm{Ne}$-лазерах при технологическом контроле.

\section{Эллипсометрия}

Для эллипсометрического анализа систем использовались данные, полученные с помощью спектрального эллипсометра „ЭЛЛИПС-1891-САГ“ (ИФП СО РАН) [19]. Измерения спектральных зависимостей эллипсометрических углов $\Psi(\lambda)$ и $\Delta(\lambda)$ проводились в диапазоне длин волн 250-1000 nm со спектральным разрешением прибора $\sim 2 \mathrm{~nm}$, время записи одного спектра не превышало $20 \mathrm{~s}$, угол падения луча света на образец составлял $70^{\circ}$. Погрешность измерений эллипсомерических углов $\Psi$ и $\Delta$ составляла \pm 0.1 arcgrad. Использовалась четырехзонная методика измерений с последующим усреднением по всем четырем зонам.

Записанные спектры $\Psi(\lambda), \Delta(\lambda)$ использовались далее для решения обратной задачи эллипсометрии (ОЗЭ) и подгонки расчетных спектральных зависимостей эллипсометрических углов $\Psi(\lambda), \Delta(\lambda)$ к экспериментальным $\Psi(\lambda), \Delta(\lambda)$ в соответствии с основным уравнением эллипсометрии

$$
\operatorname{tg} \Psi e^{i \Delta}=\frac{R_{p}}{R_{s}}
$$

где $R_{p}, R_{s}$ - комплексные коэффициенты отражения света для волн, поляризованных в плоскости падения и перпендикулярно к ней, зависящие от оптических постоянных и толщин слоев.

Подгонка спектральных зависимостей поляризационных углов во всем спектральном диапазоне для $\mathrm{m}$ точек спектра независимо осуществлялась при помощи минимизации функции ошибки

$$
\sigma^{2}=\frac{1}{2 m-k} \sum_{i=1}^{m}\left[\left|\frac{\Psi_{i}^{\exp }-\Psi_{i}^{\text {calc }}}{\delta \Psi_{i}^{\exp }}\right|-\left|\frac{\Delta_{i}^{\exp }-\Delta_{i}^{\text {calc }}}{\delta \Delta_{i}^{\exp }}\right|\right],
$$

где $\Psi_{i}^{\text {exp }}, \Delta_{i}^{\text {exp }}$ и $\Psi_{i}^{\text {calc }}, \Delta_{i}^{\text {calc }}-$ экспериментальные и расчетные значения эллипсометрических углов $\Psi$ и $\Delta$ соответственно, $\delta \Psi_{i}^{\text {exp }}, \delta \Delta_{i}^{\text {exp }}-$ величины погрешностей измерений, $m-$ число точек в спектре, $\kappa-$ число поисковых параметров.

При использовании простой оптической модели среда-пленка-подложка наблюдались хорошая подгонка расчетных эллипсометрических параметров экспериментальным и низкие значения функции (2) (таблица), что косвенно указывает на то, что исследуемые пленки изотропны и не имеют градиентов величин толщины и оптических параметров $(n, k)$ по осям $(x, y, z)$. Поэтому для расчетов $n(\lambda), k(\lambda)$ в работе использовалась оптическая модель однослойной отражающей системы, при этом расчет $n, k$ пленок проводился в каждой точке спектральных зависимостей $\Psi(\lambda)$ и $\Delta(\lambda)$ независимо. Толщины пленок определялись предварительно при многоугловых измерениях $\left(\varphi_{0}=50^{\circ}, 60^{\circ}, 70^{\circ}\right)$ в окне прозрачности пленок $(\lambda=480 \mathrm{~nm})$.

Для модельного представления рассчитанных спектральных зависимостей $n(\lambda), k(\lambda)$ использовалось приближение Лоренца-Друде [20]:

$$
\varepsilon(E)=\varepsilon_{\infty}-\frac{E_{1 D}^{2}}{E^{2}-i E_{2 D} E}+\sum_{n=1}^{m} \frac{A_{g} E_{n}^{2}}{E_{n}^{2}-E^{2}+i \Gamma_{n} E_{n} E},
$$

где $E$ - энергия фотона $(\mathrm{eV}), \varepsilon_{\infty}-$ величина $\varepsilon$ при $E \rightarrow \infty$, второй член уравнения (3) - вклад свободных носителей Друде $\left(E_{1 D}\right.$ и $E_{2 D}-$ константы); межзонные переходы описываются третьим слагаемым Лоренца на базе затухающих гармонических осцилляторов, $A_{n}, E_{n}$ и $\Gamma_{n}$ - сила, энергия и функция расширения $n$-го из $m$ осцилляторов, включенных в расчет.

Расчетные значения $n(E), \quad k(E): N(E)=\sqrt{\varepsilon(E)}$, $N(E)=n(E)-k(E) i$, получаемые из формулы Друде (3), пересчитывались далее в $n(\lambda), k(\lambda)$ и далее закладывались в уравнение (1). Формула Друде (3) использовалась для расчета в $n(\lambda), k(\lambda)$ в рамках простой оптической модели среда-пленка-подложка. Подгонка осуществлялась по всему спектру в соответствии с формулой (2) с помощью пакета MathCad. 
Состав, толщина и оптические свойства пленок на основе $\mathrm{ZnPc}$ и $\mathrm{ZnPcF}_{4}$

\begin{tabular}{|c|c|c|c|c|c|c|c|c|c|c|c|c|c|}
\hline \multirow{2}{*}{ № } & \multirow{2}{*}{ Состав } & \multirow{2}{*}{ Толщина, nm } & \multicolumn{2}{|c|}{$\lambda=632.8 \mathrm{~nm}$} & \multicolumn{6}{|c|}{ Параметры модели Лоренца-Друде } & \multirow{2}{*}{$q, \mathrm{ZnPc}$} & \multirow{2}{*}{$q$, void } & \multirow{2}{*}{$\sigma$} \\
\hline & & & $n$ & $k$ & $\varepsilon_{\infty}$ & $E_{1 D}$ & $E_{2 D}$ & $A_{n}$ & $E_{n}$ & $\Gamma_{n}$ & & & \\
\hline 1 & $\mathrm{ZnPc}$ & 49.2 & 1.543 & 0.168 & 2.011 & 0.025 & 19.8 & $\begin{array}{l}0.038 \\
0.066 \\
0.039\end{array}$ & $\begin{array}{l}2.152 \\
2.043 \\
1.729\end{array}$ & $\begin{array}{l}0.074 \\
0.123 \\
0.124\end{array}$ & - & - & 6.4 \\
\hline 2 & $\mathrm{ZnPcF}_{4}$ & 75.2 & 1.887 & 0.431 & 3.203 & 0.034 & 32.7 & $\begin{array}{l}0.032 \\
0.168 \\
0.127\end{array}$ & $\begin{array}{l}2.171 \\
1.966 \\
1.731\end{array}$ & $\begin{array}{l}0.051 \\
0.123 \\
0.110\end{array}$ & - & - & 11.7 \\
\hline 3 & $\mathrm{ZnPc}+\mathrm{ZnPcF}_{4}$ & 80.6 & 1.683 & 0.361 & - & - & - & - & - & - & 0.43 & 0.14 & 12.7 \\
\hline 4 & $\mathrm{ZnPc} / \mathrm{ZnPcF}{ }_{4}$ & 120.1 & - & - & - & - & - & - & - & - & $0.53^{*}$ & - & 8.5 \\
\hline 5 & $\mathrm{ZnPcF}_{4} / \mathrm{ZnPc}$ & 162.3 & - & - & - & - & - & - & - & - & $0.48^{*}$ & - & 4.9 \\
\hline
\end{tabular}

Примечание. * - доля толщины слоя ZnPc в общей толщине двухслойной системы.

Для описания дисперсии пленки, полученной на основе смеси фталоцианина цинка $(\mathrm{ZnPc})$ и его фторпроизводного $\left(\mathrm{ZnPcF}_{4}\right)$, использовалась модель эффективной отражающей среды Бруггемана [21]:

$$
\sum_{n}\left(q_{n} \frac{\varepsilon_{n}-\varepsilon_{\mathrm{ef}}}{\varepsilon_{n}+2 \varepsilon_{\mathrm{eff}}}\right)=0, \quad \sum_{n} q_{n}=1 .
$$

где $q_{n}$ - доля $n$-й компоненты пленки, имеющей значение диэлектрической проницаемости $\varepsilon_{n}, \varepsilon_{\mathrm{ef}}$ - суммарное значение диэлектрической проницаемости пленки.

Для эллипсометрических расчетов оптические характеристики монокристаллического кремния взяты из базы данных Adachi [22].

\section{Результаты и обсуждение}

Спектральные зависимости поляризационных углов $\Psi(\lambda)$ и $\Delta(\lambda)$ от длины волны света для тонких пленок на основе фталоцианина цинка ZnPc (образец 1) и его фторпроизводного $\mathrm{ZnPcF}_{4}$ (образец 2) показаны на рис. 1, а те же зависимости для пленок на основе смеси $\mathrm{ZnPc}+\mathrm{ZnPcF}_{4}$ (образец 3) и структуры $\mathrm{Si} / \mathrm{ZnPcF}_{4} / \mathrm{ZnPc}$ (образец 4) - на рис. 2. Решение обратной задачи эллипсометрии в соответствии с уравнением (1) показало, что пленки на основе фталоцианинов цинка сильно поглощают свет в исследуемом спектральном диапазоне. Зависимости реальной ( $n$, показатель преломления) и мнимой $(k$, коэффициент экстинкции) частей комплексного показателя преломления $N(\lambda)=n(\lambda)-i k(\lambda)$ для пленок фталоцианина цинка ZnPc и его фторпроизводного $\mathrm{ZnPcF}_{4}$, рассчитанные в соответствии с уравнением (1) для каждой точки спектра независимо, показаны на рис. 3. Спектры $n(\lambda), k(\lambda)$ имеют сложный вид и могут быть представлены совокупностью двух отдельных групп полос поглощения: коротковолновой (пики при 284, 330, $364 \mathrm{~nm}$ ) и длинноволновой (пики при 580, 630, $710 \mathrm{~nm}$ ), хорошо известных из литературы как полосы
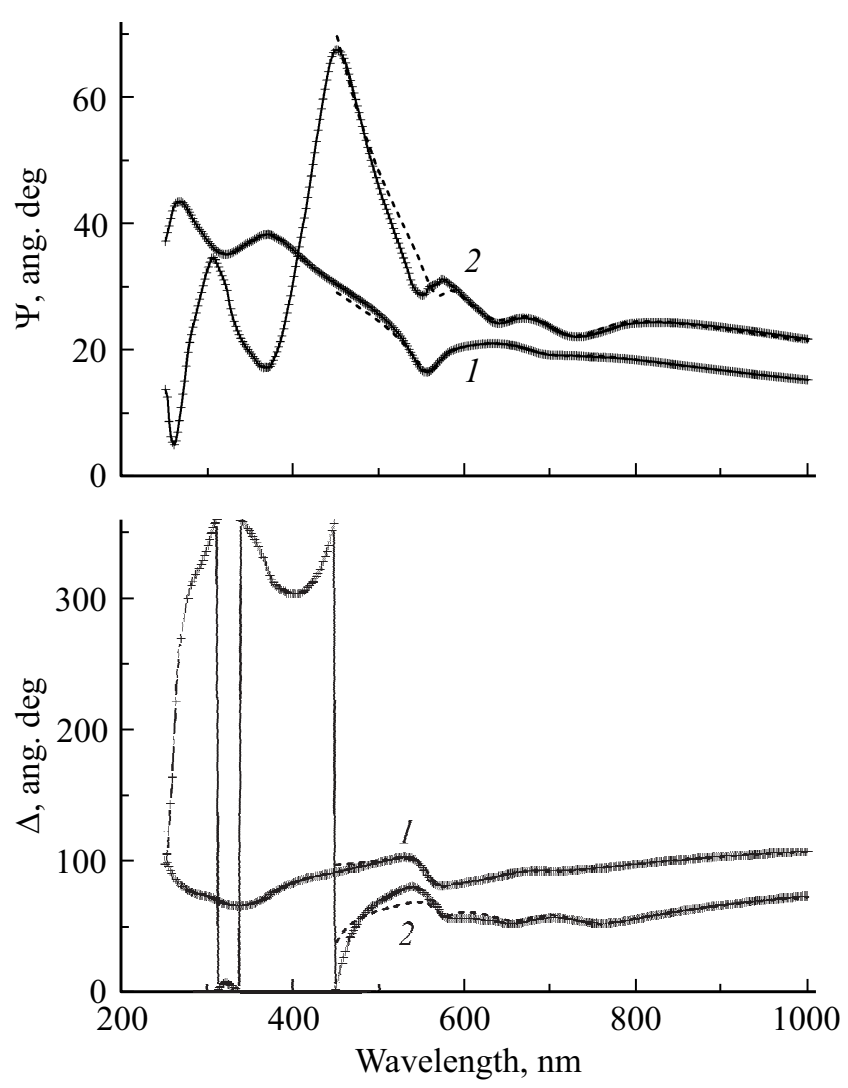

Рис. 1. Спектральные зависимости поляризационных углов $\Psi$ и $\Delta$ от длины волны света для тонких пленок фталоцианина цинка $\mathrm{ZnPc}(1)$ и его фторпроизводного $\mathrm{ZnPcF}_{4}$ (2). Пунктиром показаны расчетные данные подгонки по модели ЛоренцаДруде (3) при 450-1000 nm (см. таблицу).

Соре и $Q$ соответственно $[23,24]$. Спектры $n(\lambda), k(\lambda)$ пленок на основе $\mathrm{ZnPc}$ и $\mathrm{ZnPcF}_{4}$ различаются: дисперсионные зависимости для пленки $\mathrm{ZnPcF}_{4}$ выше, и в $Q$-группе наблюдается сдвиг пика при $580 \mathrm{~nm}$ в длинноволновую область - $630 \mathrm{~nm}$, известный в литературе как бато- 

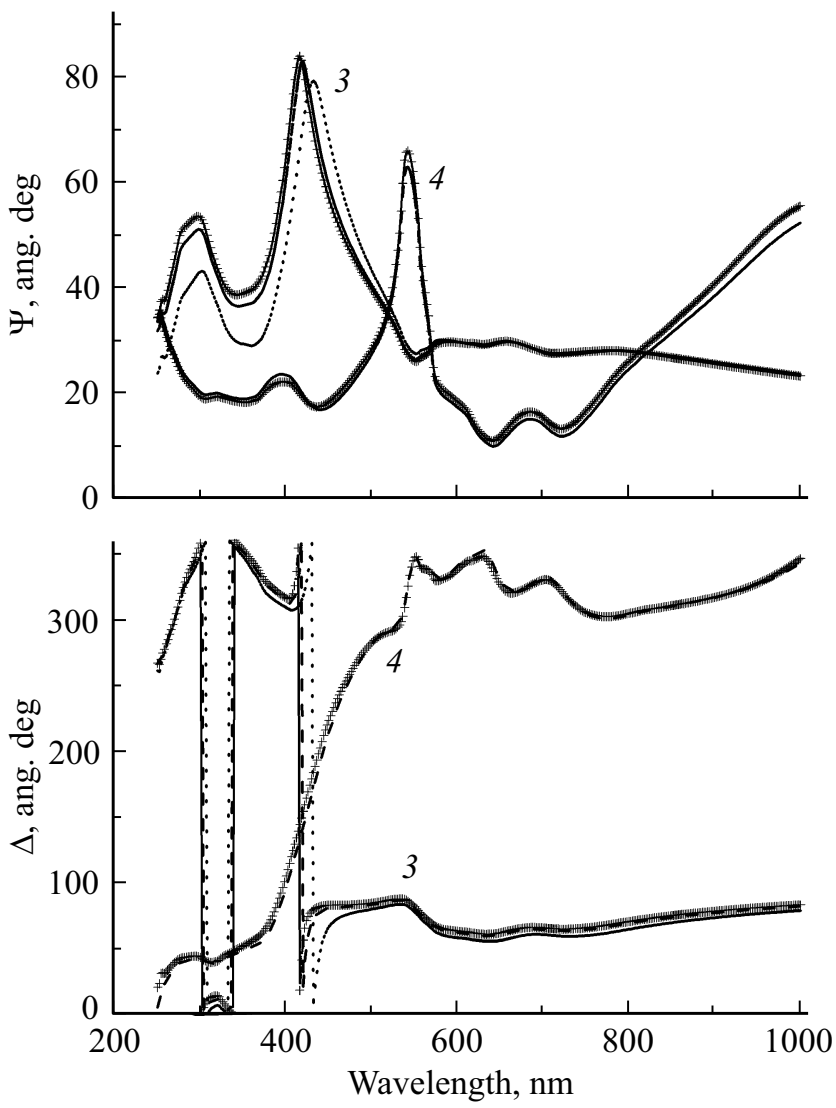

Pис. 2. Спектральные зависимости поляризационных углов $\Psi$ и $\Delta$ от длины волны света для пленки на основе смеси $\mathrm{ZnPc}+\mathrm{ZnPcF}_{4}$ (3) и структуры $\mathrm{Si} / \mathrm{ZnPcF}_{4} / \mathrm{ZnPc}$ (4). Пунктиром показаны расчетные данные подгонки по модели эффективной среды Бруггемана (4), см. таблицу и пояснения в тексте.

хромный сдвиг, который наблюдается при введении в сопряженную систему колец фталоцианина электроннодонорных заместителей. Полосы поглощения связаны с наличием сопряженной системы $\pi$-связей в молекулах фталоцианинов, поэтому фталоцианины обладают интенсивным поглощением света с коэффициентом экстинкции до $10^{5} \mathrm{M}^{-1} \mathrm{~cm}^{-1}$. $Q$-полоса соответствует поглощению света и соответственно переходу электрона с высшей заполненной молекулярной орбитали (ВЗМО) $a_{1 u}(\pi)$ на низшую свободную молекулярную орбиталь (НСМО) $e_{g}\left(\pi^{*}\right)$. При этом переход с $a_{2 u}$ на $e_{g}$ приводит к образованию полосы Cope [23,24].

Для описания подобного вида зависимостей $n(\lambda), k(\lambda)$ с видимыми максимумами поглощения хорошо подходит дисперсионная модель Лоренца-Друде на основе затухающих гармонических осцилляторов (3). В нашей работе предпринята попытка описать с помощью данной модели зависимости $n(\lambda), k(\lambda)$ для $Q$-группы $(\lambda=450-1000 \mathrm{~nm})$ в образцах 1 и 2 (таблица и рис. 1, штриховые линии). О неплохом соответствии расчетных зависимостей $\Psi(\lambda)$ и $\Delta(\lambda)$ экспериментальным свидетельствуют низкие значения величины функции ошибки $\sigma(2)$.
Для расчета толщины смешанной пленки $\mathrm{ZnPc}+$ $+\mathrm{ZnPcF}_{4}$ использовалась модель эффективной среды Бруггемана (4), при этом в качестве исходных компонент пленки использованы уже найденные дисперсионные зависимости пленок $\mathrm{ZnPc}$ (образец 1) и $\mathrm{ZnPcF}_{4}$ (образец 2). При расчетной толщине пленки $80.6 \mathrm{~nm}$ и равных долях $\mathrm{ZnPc}$ и $\mathrm{ZnPcF}_{4}$ не удается добиться хорошей подгонки расчетных значений $\Psi(\lambda), \Delta(\lambda)$ к экспериментальным (рис. 2, кривая 3, точки), которая достигается только при введении в пленку при расчетах пустот (voids) до 14\% (точечная кривая). Это может объясняться тем, что морфологии пленок $\mathrm{ZnPc}$ и $\mathrm{ZnPcF}_{4}$ различны [20], и при нанесении смешанной пленки могут возникать нестыковки в молекулярной структуре слоя, приводящие к „разрыхлению“ пленки и уменьшению дисперсионной зависимости $n(\lambda), k(\lambda)$. Двухслойные структуры $\mathrm{Si} / \mathrm{ZnPcF} 4 / \mathrm{ZnPc}$ (образец 4) и $\mathrm{Si} / \mathrm{ZnPc} / \mathrm{ZnPcF}_{4}$ (образец 5) хорошо рассчитывались с использованием найденных зависимостей $n(\lambda), k(\lambda)$ для пленок $\mathrm{ZnPc}$ и $\mathrm{ZnPcF}_{4}$ без использования переходных слоев.

Существенные изменения спектров $n(\lambda), k(\lambda)$ пленок фталоцианинов происходят при изменении их физикохимического состояния или в ходе химических реакций, что позволяет рассматривать пленки на основе фталоцианинов как перспективный материал для создания чувствительных химических сенсоров. Так, при переходе от раствора к твердому состоянию относительно узкая полоса $Q$ переходит в широкий пик с более или менее выраженным расщеплением [25]. В соответствии с теорией Давыдова степень расщепления характеризует энергию взаимодействия между молекулами, которые находятся в позициях с различной симметрией [26]. При этом полоса поглощения разделяется на несколько

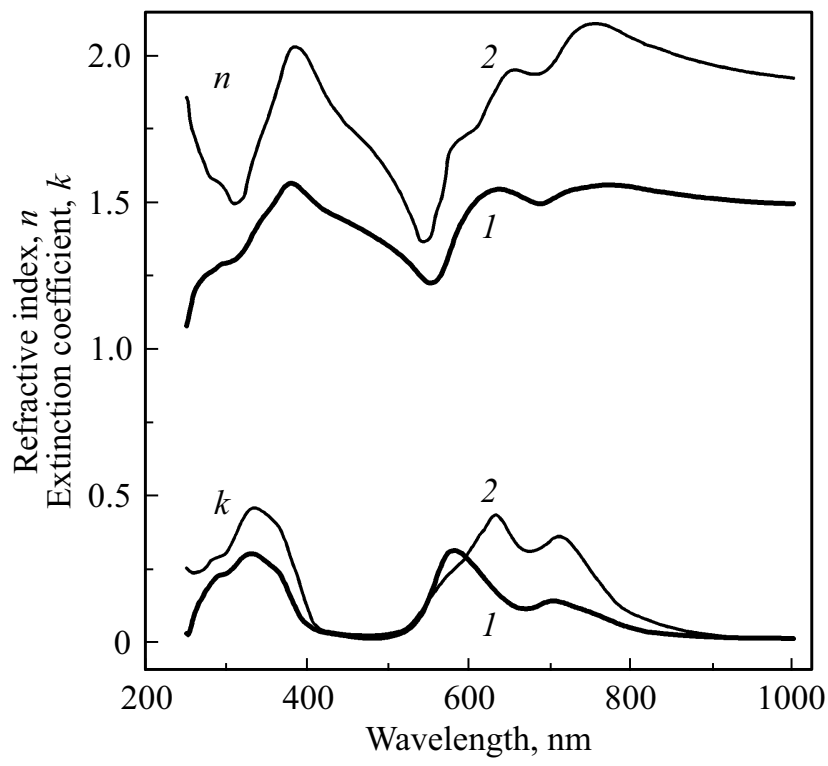

Рис. 3. Спектральная зависимость показателя преломления $N$ от длины волны (реальной $n(\lambda)$ и мнимой $k(\lambda)$ частей) для пленок фталоцианина цинка $\mathrm{ZnPc}(1)$ и его фторпроизводного $\mathrm{ZnPcF}_{4}$ (2). 
компонент. Число компонент совпадает с числом молекул, находящихся в трансляционно неэквивалентных позициях в элементарной ячейке $[27,28]$.

\section{Выводы}

Исследованы оптические свойства тонких пленок на основе незамещенного и тетрафторзамещенного фталоцианинов цинка в спектральном диапазоне длин волн 250-1000 nm, полученных методом физического осаждения из газовой фазы.

Методом спектроэллипсометрии показано, что пленки на основе фталоцианинов цинка однородны по толщине и оптическим характеристикам и сильно поглощают свет в видимой области спектра, при этом спектры поглощения света имеют характерные максимумы, обусловленные электронными переходами в молекулах фталоцианинов. Введение фторзаместителей в ароматическое кольцо фталоцианина цинка приводит к усилению поглощения света и сдвигу основного максимума поглощения в длинноволновую область спектра (батохромный сдвиг).

Для описания спектров поглощения света использована оптическая дисперсионная модель Лоренца-Друде. Показано, что пленки на основе смеси фталоцианинов могут быть хорошо описаны в рамках модели эффективной среды Бруггемана.

Работа поддержана проектом ГЗ 0306-2016-0004 и 0300-2016-0007.

\section{Список литературы}

[1] Mukherjee B., Ray A.K., Sharma A.K., Cook M.J., Chambrier I. // J. Appl. Phys. 2008. V. 103. P. 074507. doi 10.1063/1.2903061

[2] Chintakula G., Rajaputra S., Singh V.P. // Solar Energy Materials \& Solar Cells. 2010. V. 94. P. 34. doi 10.1016/j.solmat.2009.06.029

[3] Melville O.A., Lessard B.H., Bender T.P. // ACS Appl. Mater. Interfaces. 2015. V. 7. N 24. P. 13105. doi 10.1021/acsami.5b01718

[4] Birchall J.M., Haszeldine R.N., Morley J.O. // J. Chem. Soc. C. 1970. P. 2667. doi 10.1039/J39700002667

[5] Brinkmann H., Kelting C., Makarov S., Tsaryova O., Schnurpfeil G., Wöhrle D., Schlettwein D. // Phys. Stat. Sol. (a). 2008. V. 205. N 3. P. 409. doi 10.1002/pssa.200723391

[6] Schö.n J.H., Bao Z. // J. Appl. Phys. 2001. V. 89. N 6. P. 3526.

[7] Barrena E., Ossó J.O., Schreiber F., Garriga M., Alonso M.I., Dosch H.// J. Mater. Res. 2002. V. 19. N 7. P. 2061. doi 10.1557/JMR.2004.0258

[8] de Oteyza D.G., Barrena E., Ossó J.O., Sellner S., Dosch H. // J. Am. Chem. Soc. 2006. V. 128. N 47. P. 15052. doi 10.1021/ja064641r

[9] Schlettwein D., Graaf H., Meyer J.-P., Oekermann T., Jaeger N.I. // J. Phys. Chem. B. 1999. V. 103. N 16. P. 3078. doi $10.1021 / \mathrm{jp} 983111 \mathrm{~h}$

[10] Uno S., Hoshi H., Takezoe H., Ishikawa K. // Jap. J. Appl. Phys. 2005. V. 44. N 15. P. L461. doi 10.1143/jjap.44.1461
[11] Schlettwein D., Tada H., Mashiko S. // Langmuir. 2000. V. 16. P. 2872. doi 10.1021/la991111i

[12] Hashimoto S., Isoda S., Kurata H., Lieser G., Kobayashi T. // J. Porphyrins Phthalocyanines. 1999. V. 3. P. 585.

[13] Basova T.V., Kiselev V.G., Dubkov I.S., Latteyer F., Gromilov S.A., Peisert H., Chasse T. // J. Phys. Chem. C. 2013. V. 117. N 14. P. 7097. doi 10.1021/jp4016257

[14] Hiller S., Schlettwein D., Armstrong N.R., Wöhrle D. // J. Mater. Chem. 1998. V. 8. N 4. P. 945.

[15] Пляшкевич В.А.. Басова Т.В., Юиина И.В., Игуменов И.К. // Поверхность. 2008. Т. 6. С. 3.

[16] Isoda S., Hashimoto S., Ogawa T., Kurata H., Moriguchi S., Kobayashi T. // Mol. Cryst. Liq. Cryst. 1994. V. 247. P. 191. doi 10.1080/10587259408039205

[17] Klyamer D.D., Sukhikh A.S., Krasnov P.O., Gromilov S.A., Morozova N.B., Basova T.V. // Appl. Surf. Sci. 2016. V. 372. P. 79. doi 10.1016/j.apsusc.2016.03.066

[18] Klyamer D., Sukhikh A., Gromilov S., Krasnov P., Basova T. // Sensors. 2018. V. 18. P. 2141. doi 10.3390/s18072141

[19] Rykhlitskii S.V., Spesivtsev E.V., Shvets V.A., Prokop'ev V.Yu. // Prib. Tekh. Eksp. 2012. V. 2. C. 161. doi 10.4236/jasmi.2013.32014

[20] Dovbeshko G.I., Romanyuk V.R., Pidgirnyi D.V., Cherepanov V.V., Andreev E.O., Levin V.M., Kuzhir P.P., Kaplas T., Svirko Y.P. // Nanoscale Research Letters. 2015. V. 10. P. 234. doi 10.1186/s11671-015-0946-8

[21] Jaiswal J., Mourya S., Malik G., Chauhan S., Sanger A., Daipuriya R., Singh M., Chandra R. // Appl. Opt. 2016. V. 55. N 29. P. 8368. doi 10.1364/AO.55.008368

[22] Adachi S. Optical Constants of Crystalline and Amorphous Semiconductors Numerical Data and Graphical Information. NY:: Springer Science + Business Media, 1999. 763 p.

[23] Leznoff C.C., Lever A.B.P. Phthalocyanines, Properties and Application. N.Y:: VCH Publishers, 1989-1996. 941 p.

[24] Cheng W.-D., Wu D.-S., Zhang H., Chen J.-T. // Phys. Rev. B. 2001. V. 64. P. 125109 (1-11). doi 10.1103/PhysRevB.64.125109

[25] Симон Ж., Андре Ж.-Ж. Молекулярные полупроводники. Фотоэлектрические свойства и солнечные элементы. М.: Мир, 1988. 357 с.

[26] Kasha M., Rawls H.R., El-Bayoumi A. // Pure Appl. Chem. 1965. V. 11. N 3-4. P. 371. doi 10.1351/pac196511030371

[27] Hassan B.M., Li H., McKeown N.B. // J. Mater. Chem. 2000. V. 10. N 1. P. 39. doi 10.1039/A903341F

[28] Мешкова Г.Н., Вартанян А.Т., Сидоров А.Н. // Опт. и спектр. 1977. Т. 43. № 2. С. 262. 